\title{
A Rare Case of Allantoic Cyst with Patent Urachus in Fetus with a Microdeletion in 1q21.1q21.2 Region
}

\author{
Alexandra Bouariu ${ }^{1}$, Ana Maria Scutelnicu ${ }^{1}$, Anca Marina Ciobanu ${ }^{1,2}$, Brîndușa Ana Cimpoca Raptis ${ }^{1,2}$, \\ Andreea Elena Dumitru ${ }^{1}$, Florina Nedelea ${ }^{1,2,3}$, Nicolae Gică ${ }^{1,2}$ iD and Anca Maria Panaitescu ${ }^{1,2, *(D)}$ \\ 1 Filantropia Clinical Hospital Bucharest, 011117 Bucharest, Romania; alexandra.bouariu@yahoo.com (A.B.); \\ ana.scutelnicu@yahoo.com (A.M.S.); ciobanu.ancamarina@gmail.com (A.M.C.); \\ brindusa.cimpoca@gmail.com (B.A.C.R.); helena_dumitru@yahoo.com (A.E.D.); \\ ina.nedelea@gmail.com (F.N.); gica.nicolae@umfcd.ro (N.G.) \\ 2 Department of Obstetrics and Gynecology, "Carol Davila" University of Medicine and Pharmacy, \\ 020021 Bucharest, Romania \\ 3 Department of Human Genetics, Clinical Hospital Filantropia Bucharest, 011117 Bucharest, Romania \\ * Correspondence: anca.panaitescu@umfcd.ro
}

check for updates

Citation: Bouariu, A.; Scutelnicu, A.M.; Ciobanu, A.M.; Cimpoca Raptis, B.A.; Dumitru, A.E.; Nedelea, F.; Gică, N.; Panaitescu, A.M. A Rare Case of Allantoic Cyst with Patent Urachus in Fetus with a Microdeletion in 1q21.1q21.2 Region. Diagnostics 2021, 11, 2332. https://doi.org/10.3390/ diagnostics 11122332

Academic Editor: Antonio Simone Laganà

Received: 25 October 2021 Accepted: 7 December 2021 Published: 11 December 2021

Publisher's Note: MDPI stays neutral with regard to jurisdictional claims in published maps and institutional affiliations.

Copyright: (c) 2021 by the authors. Licensee MDPI, Basel, Switzerland. This article is an open access article distributed under the terms and conditions of the Creative Commons Attribution (CC BY) license (https:// creativecommons.org/licenses/by/ $4.0 /)$.
Abstract: An allantoic cyst is a rare malformation with a frequency of 3 in 1,000,000 that may be seen antenatally by ultrasound assessment when the connection between the cloaca (future bladder) and the allantois fails to regress. A patent urachus that presents as a cyst (allantoic) is usually considered not to be associated with chromosomal abnormalities, but if it is not repaired after birth this leads to complications such as urinary tract infections and stone formation. We present a case of a fetus diagnosed with allantoic cyst at the first trimester ultrasound assessment at 12 weeks gestation. The follow up scans showed a decrease in size of the allantoic cyst with no other obvious major defects and, when invasive testing (amniocentesis with microarray analysis) was performed, a rare microdeletion, 1q21.1q21.2 was identified (1.82 Mb deletion).

Keywords: allantoic cyst; umbilical cyst; fetal bladder; fetal ultrasound

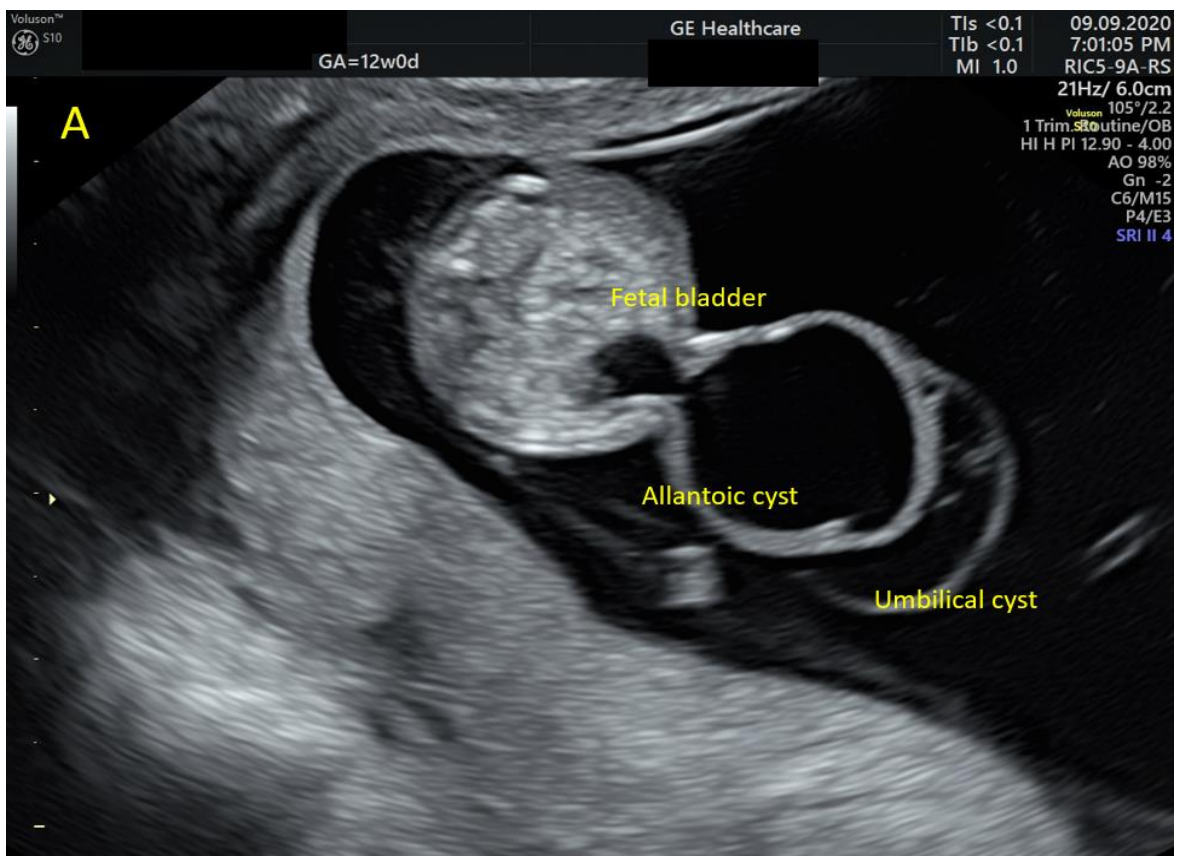

Figure 1. Cont. 

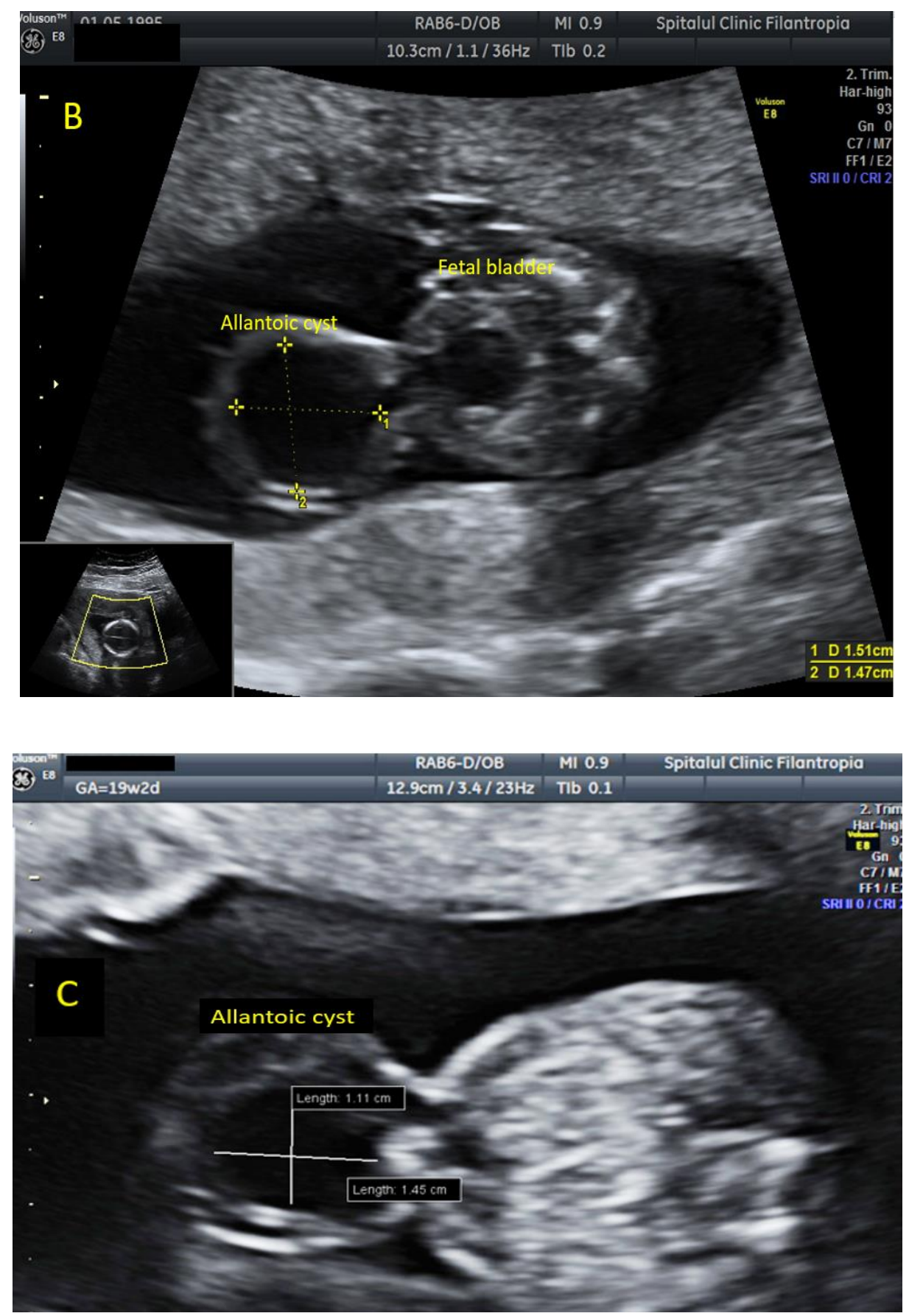

Figure 1. Cont. 


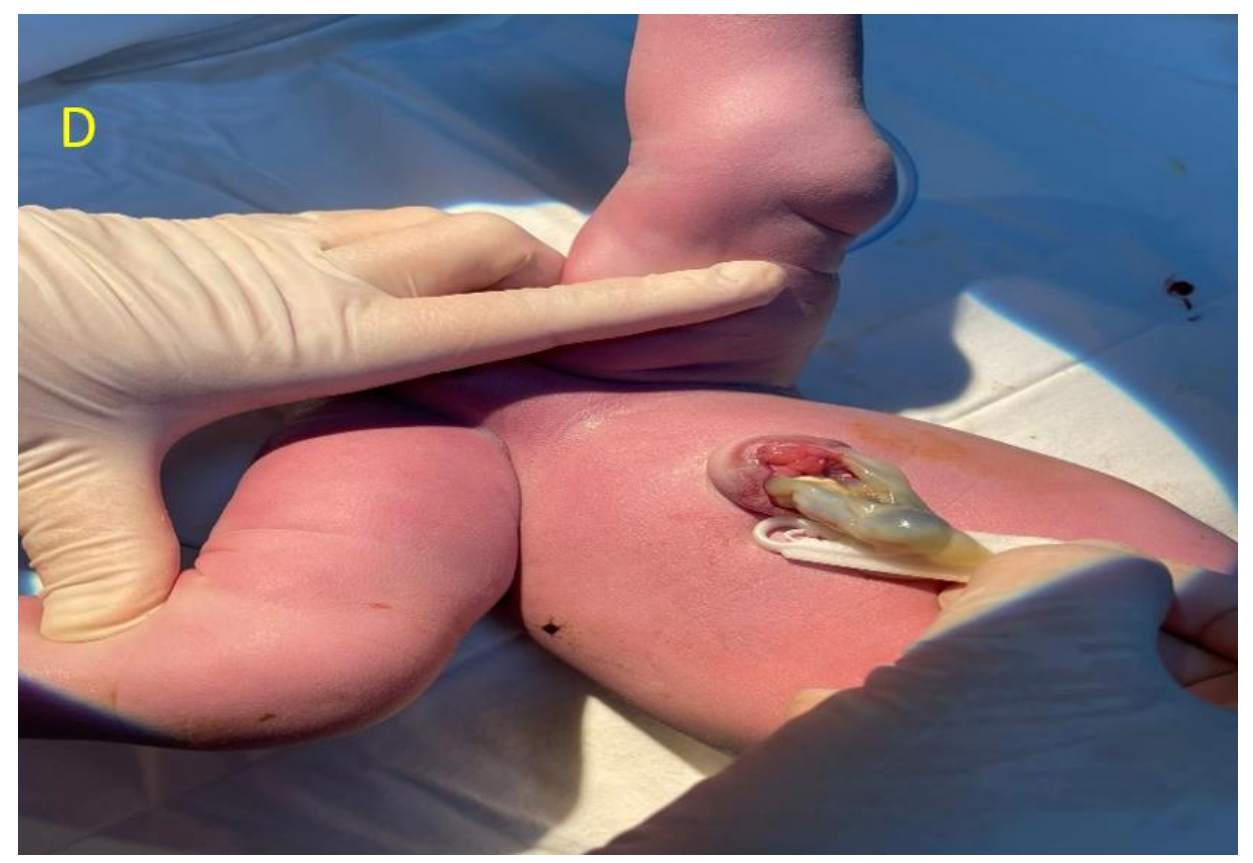

Figure 1. We present a case of a 25-year-old G3P1, fit and healthy, who presented to our unit in her first trimester for the combined screening test assessment [1,2]. The early ultrasound assessment of the fetal anatomy demonstrated a cystic structure at the level of fetal cord insertion that was connected to fetal bladder, measuring $21.1 \times 23.1 \mathrm{~mm}(\mathbf{A})$. The suspicion of allantoic cyst [3] was raised due to the patent urachus demonstrated on the ultrasound assessment [4]. An additional umbilical cyst was seen next to the allantoic cyst. Differential diagnosis with umbilical cord cyst, omphalocele and bladder exstrophy has been considered [5]. No other obvious major abnormalities have been seen and the nuchal translucency was within normal limits with a low chance for common trisomies (T21/T13/T18) from the combined screening test. A follow up scan at 16 weeks showed similar findings with the previous scan, the cystic structure keeping smaller measurements $(14.7 \times 15.1 \mathrm{~mm})(\mathbf{B})$. The anomaly scan at 19 weeks demonstrated no other structural anomalies beside the cystic structure that was measuring smaller than before $(11.1 \times 14.5 \mathrm{~mm})(\mathrm{C})$. In view of this findings, the mother chose to have invasive testing (amniocentesis), and the result of microarray showed $1.82 \mathrm{Mb}$ microdeletion in the 1q21.1q21.2 region. The consequences of 1q21.1 microdeletion may include mild developmental delay, dysmorphic craniofacial features, microcephaly, eye abnormalities, cardiac defects, brain malformations as hydrocephalus and agenesis of the corpus callosum [6,7]. Genitourinary anomalies as vesicoureteral reflux, hydronephrosis, inguinal hernia, and cryptorchidism can be present [8] Because the clinical spectrum is broad and persons with deletion do not have obvious clinical findings, the family decided to continue the pregnancy [9]. In order to establish the familial or "de novo" origin of this microdeletion, parental testing (microarray/qPCR) is advised [10]. The pregnancy evolved without complications and the third trimester scan showed small measurements of the cystic structure. A live neonate was delivered at 39 weeks by elective caesarean, weighing $3000 \mathrm{~g}$ (D). The neonate underwent surgical repair of the abdominal wall in the first weeks of life and no other complications have been reported during postnatal care. We have followed up the child within the first year of life and no dysmorphic craniofacial features, microcephaly, or renal disorders have been reported. In terms of brain development, the baby achieved the expected milestones for the first year of life including rolling over, sitting up, standing, and initially walking.

Author Contributions: Conceptualization, A.M.P. and A.B.; methodology, A.M.S.; investigation, A.M.C. and B.A.C.R.; resources, A.E.D.; data curation, F.N.; writing-original draft preparation, N.G.; writing-review and editing, A.M.P.; visualization, F.N.; supervision, N.G.; project administration, A.M.P.; All authors have read and agreed to the published version of the manuscript.

Funding: This research received no external funding. 
Institutional Review Board Statement: Not applicable.

Informed Consent Statement: Not applicable.

Conflicts of Interest: The authors declare no conflict of interest.

\section{References}

1. Veduta, A.; Vayna, A.M.; Duta, S.; Panaitescu, A.; Popescu, F.; Bari, M.; Peltecu, G.; Nedelea, F. The first trimester combined test for aneuploidies-A single center experience. J. Matern. Neonatal Med. 2017, 31, 2091-2096. [CrossRef] [PubMed]

2. Vayna, A.M.; Veduta, A.; Duta, S.; Panaitescu, A.M.; Stoica, S.; Buinoiu, N.; Nedelea, F.; Peltecu, G. Diagnosis of Fetal Structural Anomalies at 11 to 14 Weeks. J. Ultrasound Med. 2018, 37, 2063-2073. [CrossRef] [PubMed]

3. Walsh, P.; Retik, A.; Vaughan, E.D., Jr.; Wein, A.J.; Kavoussi, L.R.; Novick, A.C. Other bladder anomalies. In Campbell's Urology, 8th ed.; Saunders: Philadelphia, PA, USA, 2002; pp. 2189-2191.

4. Yu, J.-S.; Kim, K.W.; Lee, H.-J.; Lee, Y.-J.; Yoon, C.-S.; Kim, M.-J. Urachal remnant disease: Spectrum of CT and US findings. Radiographics 2001, 21, 451-461. [CrossRef] [PubMed]

5. Umeda, S.; Usui, N.; Kanagawa, T.; Yamamichi, T.; Nara, K.; Ueno, T.; Owari, M.; Uehara, S.; Oue, T.; Kimura, T.; et al. Prenatal and Postnatal Clinical Course of an Urachus Identified as an Allantoic Cyst in the Umbilical Cord. Eur. J. Pediatr. Surg. 2016, 26, 200-202. [PubMed]

6. Haldeman-Englert, C.R.; Jewett, T. 1q21.1 Recurrent Microdeletion. GeneReviews 2015, 8, 93-97.

7. Mefford, H.; Hulten, M. 1q21.1 microdeletions. Unique 2014, 16, 359.

8. Riddell, J.V.B.; Houle, A.; Franc-Guimond, J.; Barrieras, D. Prenatal vesico-allantoic cyst outcome-A spectrum from patent urachus to bladder exstrophy. Prenat. Diagn. 2015, 35, 1342-1346. [CrossRef] [PubMed]

9. Morichon-Delvallez, N. 1q21.1 Microdeletion Syndrome. March 2011. Available online: https://www.orpha.net/consor/cgi-bin/ OC_Exp.php?lng=EN\&Expert=250989 (accessed on 26 October 2021).

10. Harvard, C.; Strong, E.; Mercier, E.; Colnaghi, R.; Alcantara, D.; Chow, E.; Martell, S.; Tyson, C.; Hrynchak, M.; McGillivray, B.; et al. Understanding the impact of 1q21.1 copy number variant. Orphanet J. Rare Dis. 2011, 8, 54. [CrossRef] [PubMed] 